\title{
Cotton Utilization in Conventional and Non-Conventional Textiles-A Statistical Review
}

\author{
Mourad Krifa*, Sara Stewart Stevens \\ Department of Textiles and Apparel, The University of Texas, Austin, TX, USA \\ Email: *Mourad.krifa@austin.utexas.edu
}

How to cite this paper: Krifa, M. and Stevens, S.S. (2016) Cotton Utilization in Conventional and Non-Conventional TextilesA Statistical Review. Agricultural Sciences, 7, 747-758

http://dx.doi.org/10.4236/as.2016.710069

Received: September 17, 2016

Accepted: October 24, 2016

Published: October 27, 2016

Copyright $\odot 2016$ by authors and

Scientific Research Publishing Inc.

This work is licensed under the Creative

Commons Attribution International

License (CC BY 4.0).

http://creativecommons.org/licenses/by/4.0/

\begin{abstract}
World textile fiber demand was 89.8 million tons in 2015 and is expected to grow to 93.7 million tons in 2016. Global demand for textile fibers is driven by population growth and by economic activity resulting in increasing wealth, particularly in emerging economies. While this overall trend is consistent across most major fibers, there are substantial disparities in the demand patterns of natural versus man-made fiber, with cotton and polyester being the primary protagonists. This paper charts recent trends and potential opportunities relevant to cotton fiber utilization in conventional and non-conventional textile products.
\end{abstract}

\section{Keywords}

Cotton Utilization, Textiles, Clothing, Nonwovens, Market

\section{Introduction}

Cotton's success as a crucial raw material for the textile industry is unparalleled among all natural and manmade fibers. Cotton fibers have been used in virtually all categories of textiles because they combine physical and chemical characteristics that make them versatile in processing and desirable in use [1] [2]. In addition, progress in cotton farming and rapid growth in lint production in response to the surge in fiber demand since the early days of the industrial revolution have placed cotton on top of the global textile fiber market for over 200 years [3].

Cotton utilization in textiles is dominated by the clothing sector which consumes close to two thirds of the lint produced globally, followed by home furnishings then industrial textiles with less than $10 \%$ [4] [5]. Cotton's competitiveness on the textile market is continuously impacted by evolution in consumer demand and by rapid development in the manmade fiber production sector. In the following sections, we offer a 
statistical review of the historical patterns and current dynamics in the global textile fiber market. We then review the primary uses of cotton textiles in consumer products based on U.S. market statistics and discuss the related challenges and opportunities faced by the cotton industry.

\section{Cotton's Market Share}

As mentioned above, cotton has for the most part of the last two centuries been the dominant fiber on the global textile market. Until the 1960s, more than two thirds of all textile fibers consumed worldwide consisted of cotton [6]. With the advent and rapid development in petrochemical synthetic fibers driven notably by polyester, cotton's market share has declined significantly to under $30 \%$ in 2015 [6]. With the growth of the world's population, demand for textile fibers is projected to grow at an estimated $3.9 \%$ annual average, with an increasing portion of this demand being met by synthetic fibers. Figure 1 depicts the global demand for textile fibers from 1960 to 2015. Global demand of all fibers combined was close to 90 million tons in 2015, which corresponds to a world average of approximately $12.5 \mathrm{~kg}$ per capita [6]. Of the total demand, 59.6 million tons consisted of synthetic fibers (manmade non cellulosic) and only 24.8 million tons consisted of cotton. This corresponds to a cotton market share of approximately 27\%. As shown in Figure 1, these market shares are the result of a consistent pattern where synthetic fiber demand growth has outpaced that of cotton since 1960. Thus, cotton's market share of the world textile fiber market has steadily declined, with the exception of a notable plateau over the 1980s.

It is also notable that the decline in cotton market share accelerated substantially following the 2008 global recession. While demand for all fibers has plunged during that period, synthetic fibers recovered much faster than cotton. Indeed, cotton consumption continued to decline, or at best stagnate, until 2012-13 because of historically high cotton prices (Figure 2) resulting in a trend of fiber substitution in favor of synthetic fibers [7] [8]. Figure 2 shows clearly the poor price competitiveness of cotton in the years following 2009-10 when compared to polyester. Polyester is the main competitor as it represented in 2014 a share of $82 \%$ of the synthetic staple fiber market [9].

In addition to price competiveness as illustrated in Figure 2, synthetic fiber producers have virtually unlimited production capacity and unlimited ability to manipulate fiber properties. On the other hand, cotton is faced with limited farmland and no direct way of manipulating the naturally occurring and highly variable properties of the fibers [10] [11]. Therefore, addressing the challenge of interfiber competition by the cotton industry starts at the production level. In addition to optimizing farming practices, one path to increasing production with the limited farmland resources is through genetic improvement of the plant for better yield and fiber quality. Constantly seeking better yields is important not only to maintain farm operation profitability, but also to satisfy the fiber demands of a growing world population. In the particular case of cotton, increasing farmland area to meet the rapidly expanding demand for textiles is not a viable option [12]. Figure 3 shows that the farmland area cultivated to cotton has essentially 


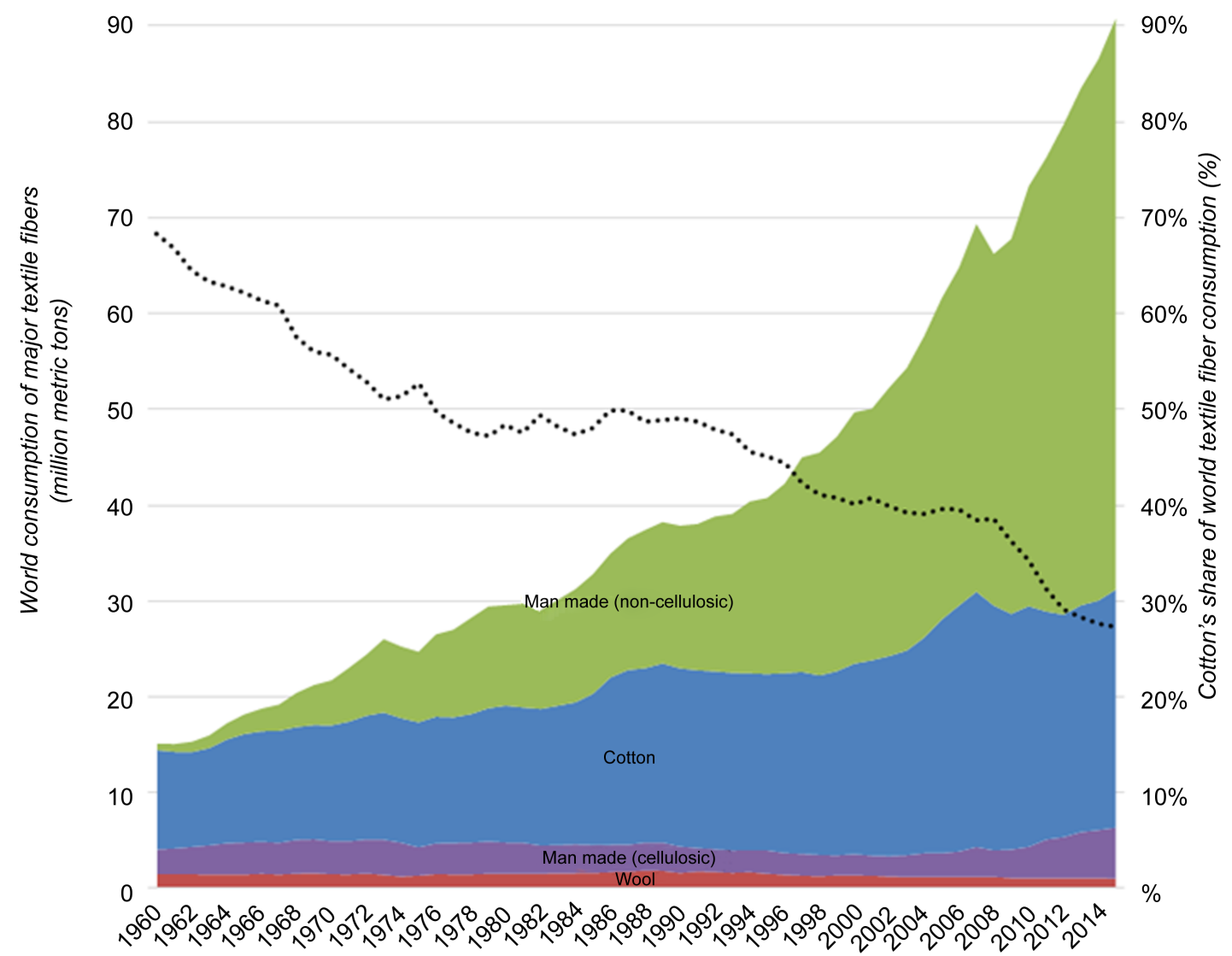

Figure 1. World consumption of major textile fibers and variation of cotton's market share [6].
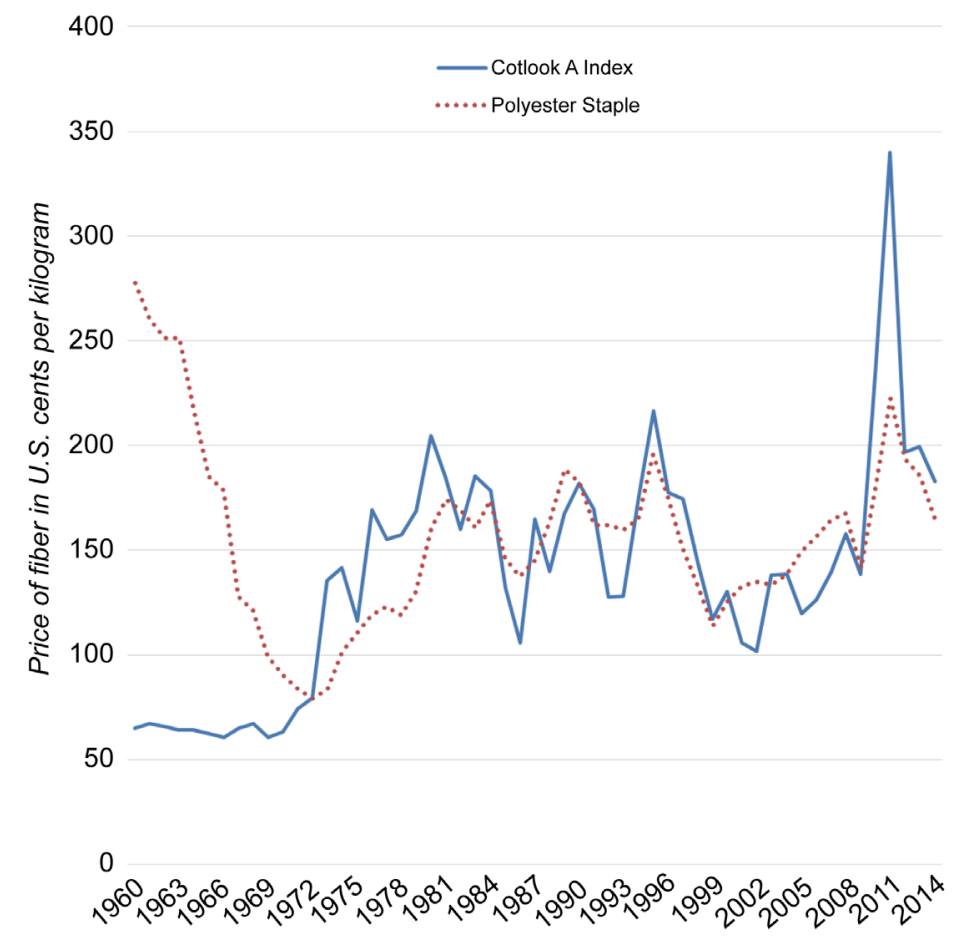

Figure 2. Prices of cotton (Cotlook A Index) and polyester staple fibers from 1960 to 2014 [6]. 


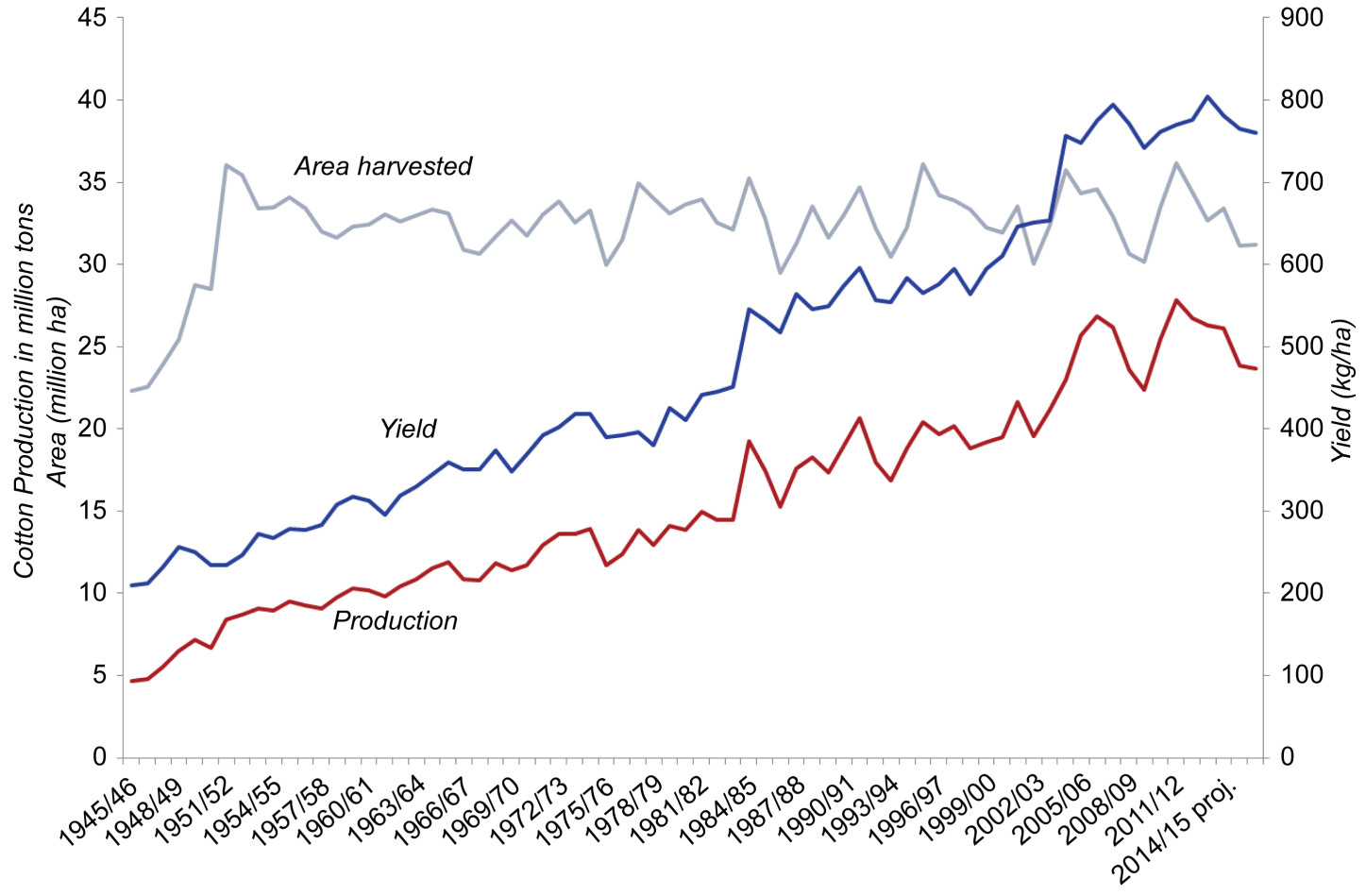

Figure 3. Growth in cotton yield and world production with constant farmland area [6].

reached a plateau since 1950 [6]. Considering these limited land resources, cotton varieties with improved yield potential are critical to maintaining growth in cotton production and to providing a viable natural fiber alternative to petroleum-based synthetics. Thus, cotton world production has seen a steady long-term growth driven by consistently improving yields since the mid-1940s (Figure 3).

\subsection{Cotton Utilization in Conventional Textile Products}

As stated above, clothing and home furnishings represent the primary textile uses for cotton fibers. Those applications consist of primarily woven or knitted textiles and are collectively referred to as conventional textiles. To illustrate cotton's competitiveness in various segments of the textile and apparel market, we examine data compiled by the United States International Trade Commission which provides detailed annual trade data relevant to all categories of textile and apparel products [13].

Consumers tend to associate cotton with physical and psychological comfort and favor it in applications that come in intimate contact with their body and close environment [14] [15] [16]. Consequently, when considering demand for clothing and home furnishing applications, cotton's market share is consistently found to be in excess of $50 \%$. For instance, Figure 4 shows that cotton represented $54 \%$ of all articles of apparel and $56 \%$ of home furnishings imported to the U.S. market in 2015.

Within the apparel market, cotton competitiveness varies according to end-use consumer groups and specific product categories (Figure 5). Indeed, cotton filled more than $80 \%$ of the baby clothing demand in 2015 , compared to $67 \%$ of the men and boy 

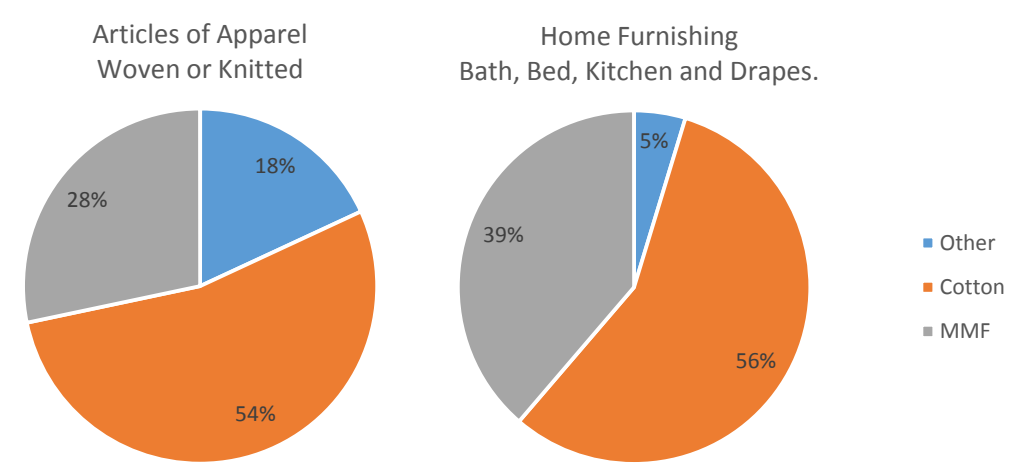

Figure 4. Major fiber U.S. market share in apparel (left) and home furnishing.

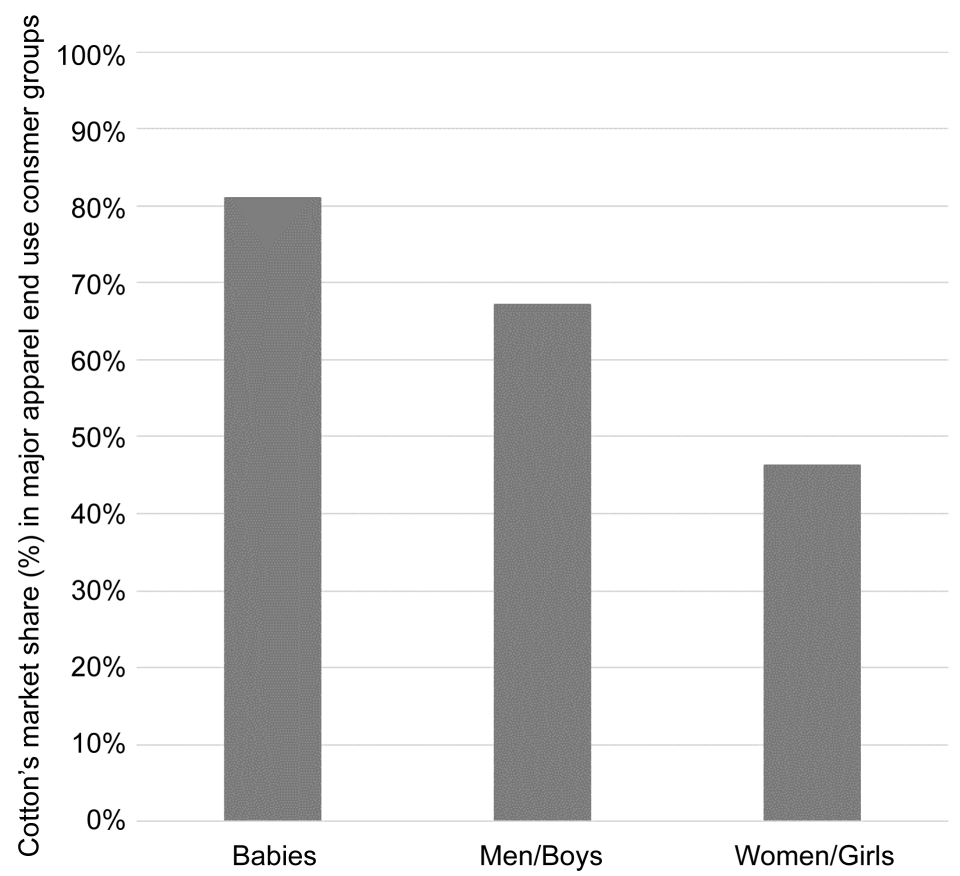

Figure 5. Cotton's apparel market share (\%) by major end-use consumer group; 2015 U.S. imports [13].

apparel demand, and a low $46 \%$ of the women \& girl market (Figure 5). The large dominance of the baby apparel segment is indicative of the image consumers have of cotton as a safe and comfortable natural fiber they trust in their babywear [15] [17] [18] [19]. On the other end of the spectrum, women's apparel appears to be a sizeable challenge for the cotton industry.

Women's wear makes up $60 \%$ of the overall apparel market [20]. In addition to differing in apparel selection processes, men and women differ in their use of clothing. The women's apparel sector is more complex due to ample aesthetic options, with a broad adherence to fashion trends and a quest for personal differentiation through apparel [20]. Consequently, major products of women apparel tend to represent challenges for cotton primarily because of aesthetic reasons. Such is the case of the dresses product category, for example, in which cotton held a meager $20 \%$ market share in 
2015 [13]. Men \& boys' apparel categories on the other hand appear to represent a better competitive edge for cotton. For both genders, the apparel categories that top the ranking in terms of cotton market share are bottoms, tops, as well as underwear and nightwear.

As mentioned previously, home furnishing products represent the second major market for cotton utilization behind clothing. Figure 6 depicts cotton's market share in major home furnishing product categories in a similar way as above. Cotton remains exceptionally dominant in the bath \& kitchen linen category with a market share of $97 \%$. Bed linen follows with $66 \%$, followed by table linen with a $33 \%$ market share. At the other end of the spectrum, cotton appears challenged by synthetic fiber competition in the blanket and curtain/drapes categories, with a market share of $16 \%$ and $14 \%$, respectively.

Based on the market statistics discussed above, cotton continues to thrive in many conventional textiles that come in close contact with consumers, i.e., where comfort and safety come to the forefront of concerns. Such products include babywear, underwear and nightwear as well as bath/kitchen linen. Cotton's natural properties offer unparalleled comfort to textile and apparel consumers. Research conducted on multiple consumer groups worldwide indicates that the comfort consumers associate with cotton is both physical and psychological [14] [15]. Thus, although cotton has been losing market share of the overall textile fiber demand, it remains the raw material of choice in textile and apparel applications used as part of consumers intimate environment.

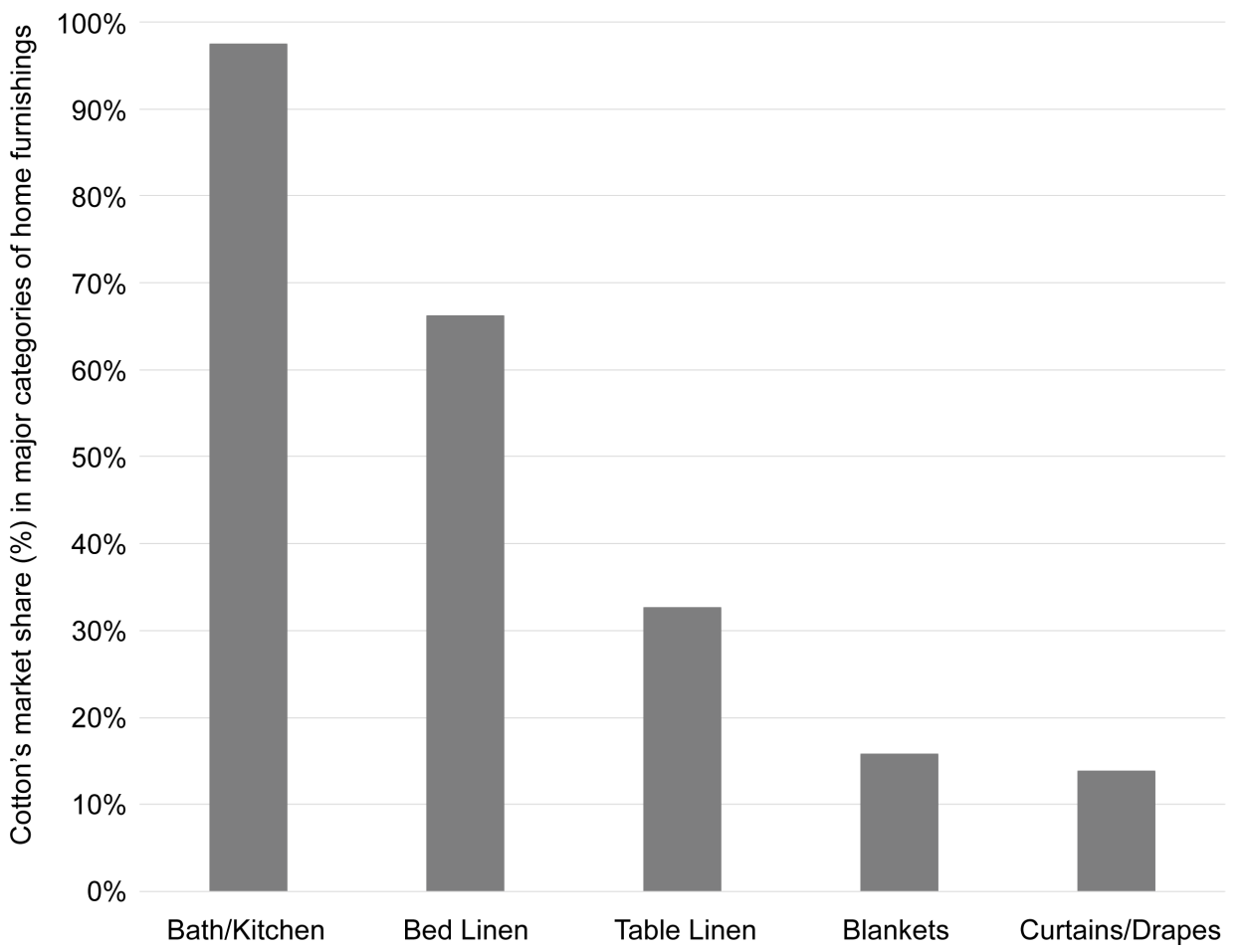

Figure 6. Cotton's market share (\%) of major categories of home furnishing applications; 2015 U.S. imports [13]. 


\subsection{Cotton Utilization in Non-Conventional Textile Products}

Current and projected market growth in technical and non-conventional textiles, including nonwoven products, outperforms that of conventional textiles on a global scale. Indeed, nonwovens are the fastest growing sector in the textile field in both developed and emerging markets [21] [22] [23] [24] [25]. According to the Fiber Year Consulting group [9], nonwovens and unspun textile end-uses represented 10.9 million tons in 2014, up 4.2\% from the previous year. Other reports show annual growth rates in the double-digits for key sectors in emerging markets. For instance, an INDA report [24] cites a 17\% annual growth of China's nonwoven industry between 2003 and 2008, and a $12 \%$ growth rate up to 2013 .

Nonwoven materials are increasingly becoming a part of people's day to day life worldwide. They are used in applications varying from household and personal wipes to industrial and automotive materials. Thus, the fast growth evidenced in those market reports is driven by a combination of factors impacting demand for household goods, personal care and hygiene products, as well as technical applications such as the construction or automotive sectors [23] [24] [25]. Population and personal income growth leading to rising standards of living in emerging economies drive demand for nonwovens used in diapers, sanitary napkins, and wipes [23] [24] [25]. In addition, as investment in infrastructure and construction regains steam after years of economic recession and slow recovery, demand for geotextiles and nonwoven-based construction components has seen a boost [23]. Nonwovens have also been penetrating markets historically served by woven fabrics because of potential advantages in both cost and performance [26].

Nonwoven processing technology was once seen by the cotton industry as a tool to reclaim waste from conventional processing of cotton [27]. For instance, resin-bonded short cotton waste was proposed for industrial wipes [27]. More recently, use of cotton in nonwovens became limited to scoured and bleached fibers because greige cotton represented major processing challenges due to impurities. Bleached cotton is utilized in the wipes, hygiene and health product category. However, even considering these applications, cotton's market share is minute and does not exceed a few percentage points [28].

While geotextiles and construction materials represent durable structures, the vast majority of nonwoven products used in household, hygiene and personal care applications are disposable [29] [30] [31] [32] [33]. The reported market share between durable and disposable nonwoven products varies according to sources, primarily because of inconsistent classification of filtration materials [34]. For instance, disposable products accounted for up to $39 \%$ of all nonwoven production according to EDANA estimates cited by Kiekens and Zamfir [32]. More recently, Rupp [33] noted that the market breakdown is $65 \%$ disposable and $35 \%$ durable, with the disposable portion growing at a more sustained rate.

Regardless of the source and specific percentage share, there is broad agreement that end-of-life disposal and the massive amount of waste that single-use convenience non- 
woven products engender is becoming a key challenge. Indeed, the non-conventional textile industry is quasi-monopolized by synthetic fibers, particularly polypropylene in the hygiene market and polyester in durable household, construction and other applications [25] [29] [30] [32]. This is due to numerous factors including uniformity of manmade fibers and ease of manipulating fiber properties using additives and processing parameters [25] [29] [30] [32]. However, the rapidly growing volume of disposable applications and the lack of biodegradability of synthetic fibers raise concerns about waste disposal and its environmental impacts. Consequently, there is more and more interest in using more natural fibers in nonwoven applications because of their biodegradability and availability from renewable resources.

Thus, growing concern about issues related to waste disposal and product biodegradability is motivating a shift from the use of petroleum based synthetic fibers to natural fibers in nonwoven products. This shift towards natural fibers has been seen in the automotive industry, which uses nonwoven materials for boot liners, shelf trim, oil and cabin air filters, molded bonnet liners, heat shields etc. [35]. In order to promote the use of environmentally safe products in vehicles, legislatures in the U.S and Europe have issued special directives to incorporate recyclable and biodegradable fibers in nonwovens used in automotive components. The directive, which came into effect at the turn of the century, predetermined the deposition fraction of a vehicle to be $15 \%$ for the year 2005, and gradually to be reduced to $5 \%$ for the year 2015 [36]. This new demand has been met by extensive research on incorporating cellulosic fibers in automotive parts and other durable nonwoven- and biocomposite-based engineering materials. Examples of fibers suggested for such application include commonly known candidates such as hemp, bagasse, kenaf, and ramie [37] [38], as well as new explorations including Agave Americana L. and Alfa or esparto grass plant fibers [39] [40] [41] [42].

Cotton has also been evaluated by some studies focusing on durable technical applications [36] [43]. However, the potential for expanded cotton utilization is more substantial in hygiene products and other non-durable or disposable applications that come in close contact with consumers. In addition to biodegradability, cotton's absorbency, softness, comfort and natural feel make it stand as the natural alternative for Hygiene and next-to-skin applications [30] [32] [44]. Furthermore, consumer behavior research consistently shows a clear preference by consumers of cotton or "cotton-enhanced" products in the applications that generate the massive and fast growing waste going to landfills, i.e., disposable hygiene and personal care products [30] [32] [44].

In addition to the potential in hygiene products, studies in the early to mid-1990s by Choi et al. [45] [46] [47] focused on the potential of cotton needle punched nonwovens as oil spill cleanup aid. The authors investigated the effectiveness of cotton nonwovens in different blend ratios with polypropylene ( $100 \%$ cotton, $80 \%$ cotton/20\% polypropylene, $65 \%$ cotton $/ 35 \%$ polypropylene and $50 \%$ cotton $/ 50 \%$ polypropylene, and $100 \%$ polypropylene). They found that "partial or complete replacement of synthetic sorbent with cotton is possible as an oil spill cleanup application" [45]. In a recent flare of interest in this application following the Deepwater Horizon oil spill in 2010, it was sug- 
gested that immature cotton would perform better than mature cotton and improve the performance features described by Choi et al. [45]. Kiekens and Zamfir [32] examined needle-punched cotton nonwovens for use in absorbent products and derived equations modeling absorption parameters as a function of processing conditions (feed rate and punching rate). More recent studies focused on use of non-bleached greige cotton to process mechanically entangled nonwovens through needle-punching or hydro-entanglement [28] [48] [49]. Suggested applications include major disposable items such as personal-care and hygiene products as well as durable or semi-durable goods such as upholstery and padding inserts for other household textiles [48].

\section{Conclusion}

Cotton has reigned over the global textile fiber market for the major part of the last two centuries because it combines a unique set of intrinsic characteristics that make it a raw material of choice for processors. In addition, cotton enjoys a privileged relationship with consumers who tend to trust it as a natural and safe choice in sensitive applications such as babywear and next-to-skin clothing. As a result, cotton continues to thrive in such applications despite an overall decline of its competitiveness when considering the global demand for textile fibers. Synthetic fiber growth continues to outpace that of cotton in other conventional textile applications, and most notably in the non-conventional market served by the nonwoven industry. Nevertheless, continuous research efforts are leading to new opportunities for expanding cotton utilization in those market segments.

\section{References}

[1] Collier, B.J., Bide, M.J. and Tortora, P.G. (2009) Understanding Textiles. 7th Edition, Pearson Prentice Hall, Upper Saddle River, 564 p.

[2] Kadolph, S.J. (2010) Textiles. 11th Edition, Pearson, Boston, 581 p.

[3] Rivoli, P. (2009) The Travels of a T-Shirt in the Global Economy: An Economist Examines the Markets, Power, and Politics of World Trade. 2nd Edition, John Wiley, Hoboken, 316 p.

[4] AgriLogic Inc. (2003) Upland Cotton: An Economic Assessment of Providing Cost of Production Insurance. USDA-Risk Management Agency, Kansas City, p. 79.

[5] FAO (2009) Natural Fibers-Cotton. http://www.naturalfibres2009.org/en/fibres/cotton.html

[6] ICAC (2015) World Textile Demand. International Cotton Advisory Committee, Washington DC, p. 146.

[7] Cotton Incorporated (2010) Framing the Cotton Pricing Discussion. Cotton Incorporated Supply Chain Insights.

[8] Cotton Incorporated (2011) Rising Prices: Will Consumers Pay? Cotton Incorporated Supply Chain Insights.

[9] The Fiber Year GmbH (2015) The Fiber Year 2015. In: Engelhardt, A., Ed., World Survey on Textiles and Nonwovens Industry, The Fiber Year GmbH, Speicher, p. 218.

[10] Krifa, M. (2012) Fiber Length Distribution Variability in Cotton Bale Classification: Interactions among Length, Maturity and Fineness. Textile Research Journal, 82, 1244- 
1254. http://dx.doi.org/10.1177/0040517512438124

[11] Krifa, M. (2013) Cotton Fiber Length Distribution Modality Alteration in Ginning and Mill Processing. The Journal of The Textile Institute, 104, 731-744. http://dx.doi.org/10.1080/00405000.2012.754117

[12] Cantrell, R.G. (2006) The Role of Biotechnology in Improving the Sustainability of Cotton. 65 th Plenary Meeting of the International Cotton Advisory Committee, International Cotton Advisory Committee, Goiânia, 6-12.

[13] United States International Trade Commission (2016) Interactive Tariff and Trade DataWeb.

[14] Byrne, M.S., Caton, S.T. and Pelton, W. (1998) Perceptions of Fibre Types: A CrossCultural Study into the Effects of Textile Education. Journal of Consumer Studies \& Home Economics, 22, 209-214. http://dx.doi.org/10.1111/j.1470-6431.1998.tb00731.x

[15] Boslet, R.J. (1989) Why Cotton Sells, in Textile Asia. Business Press, Hong Kong, p. 161, 203.

[16] Krifa, M. and Stewart Stevens, S. (2013) Cotton Utilization in Apparel Products: A Statistical Review in Beltwide Cotton Conferences. National Cotton Council of America, San Antonio.

[17] Schneider, A.M. and Holcombe, B.V. (1991) Properties Influencing Coolness to the Touch of Fabrics. Textile Research Journal, 61, 488-494. http://dx.doi.org/10.1177/004051759106100810

[18] Schneider, A.M., Holcombe, B.V. and Stephens, L.G. (1996) Enhancement of Coolness to the Touch by Hygroscopic Fibers: Part I: Subjective Trials. Textile Research Journal, 66, 515-520. http://dx.doi.org/10.1177/004051759606600805

[19] Li, Y., Holcombe, B.V. and De Dear, R. (1996) Enhancement of Coolness to the Touch by Hygroscopic Fibers: Part II: Physical Mechanisms. Textile Research Journal, 66, 587-594. http://dx.doi.org/10.1177/004051759606600907

[20] Thiry, M. (2008) The Power of Womenswear. AATCC Review, 18-27.

[21] Chang, W. and Kilduff, P. (2002) The US Market for Technical Textiles, in SBTDC Technical Textiles Industry Study 2002. Small Business Technology Development Center, Raleigh, 32.

[22] David Rigby Associates (2002) Technical Textiles and Nonwovens: World Market Forecasts to 2010. David Rigby Associates, Manchester, 17.

[23] Carrigg, R. and Alarid, R. (2016) 2016 Top Markets Report: Technical Textiles. International Trade Administration, $56 \mathrm{p}$.

[24] INDA (2012) Emerging Market Opportunities for Nonwovens Companies, in Vision Series. Association of the Nonwovn Fabrics Industry, 6.

[25] Grand View Research (2015) Nonwoven Fabrics Market Analysis by Product (Polypropylene, Polyesters, Nylon), Technology (Spunlaid, Carded, Air Laid, Wet Laid), Application (Durable, Disposable) and Segment Forecasts to 2020.

http://www.grandviewresearch.com/industry-analysis/nonwoven-fabrics-market

[26] Ernster, B. (2012) The growing Nonwovens Market. Specialty Fabrics Review, Industrial Fabrics Association International.

[27] Kalebek, N.A. and Babaarslan, O. (2016) Fiber Selection for the Production of Nonwovens. In: Jeon, H.-Y., Ed., Non-Woven Fabrics, InTech, Chapter 1. http://dx.doi.org/10.5772/61977

[28] Sawhney, A., Reynolds, M., Allen, H., Slopek, R. and Condon, B. (2013) Effects of Greige 
Cotton Lint Properties on Hydroentangled Nonwoven Fabrics. Textile Research Journal, 83, 3-12. http://dx.doi.org/10.1177/0040517512452949

[29] Moreau, J.P. (1990) Cotton Fiber for Nonwovens. Tappi Journal, 73, 179-185.

[30] Goynes, W.R., Moreau, J.P., Delucca, A.J. and Ingber, B.F. (1995) Biodeterioration of Nonwoven Fabrics. Textile Research Journal, 65, 489-494. http://dx.doi.org/10.1177/004051759506500809

[31] Wadsworth, L.C., Suh, H. and Allen Jr., H.C.A. (2000) Cotton-Surfaced Nonwovens For Short-Wear-Cycle Apparel. International Nonwovens Journal, 9, 47-54.

[32] Kiekens, P. and Zamfir, M. (2002) Non-Wovens from Cotton Fibers for Absorbent Products Obtained by the Needle-Punching Process. Autex Research Journal, 2, 166-174.

[33] Rupp, J. (2009) Nonwovens Made of Cotton. Textile World, Billian Publishing Inc., Jan/Feb 2009. http://www.textileworld.com/

[34] Rupp, J. (2010) Nonwovens Focus: Human-Centered Applications. Textile World.

[35] Massenaux, G. (2003) Introduction to Nonwovens. In: Albrecht, W., Fuchs, H. and Kittelmann, W., Eds., Nonwoven Fabrics, Wiley-VCH, Weinheim, 1-12.

[36] Kamath, M.G., Bhat, G.S., Parikh, D.V. and Mueller, D. (2005) Cotton Fiber Nonwovens For Automotive Composites. International Nonwovens Journal, 14, 34-40.

[37] Chen, Y., Chiparus, O., Sun, L., Negulescu, I., Parikh, D.V. and Calamari, T.A. (2005) Natural Fibers for Automotive Nonwoven Composites. Journal of Industrial Textiles, 35, 47-62. http://dx.doi.org/10.1177/1528083705053392

[38] Chen, Y., Sun, L., Negulescu, I., Wu, Q. and Henderson, G. (2007) Comparative Study of Hemp Fiber for Nonwoven Composites. Journal of Industrial Hemp, 12, 27-45. http://dx.doi.org/10.1300/J237v12n01_04

[39] Chaabouni, Y., Drean, J.-Y., Msahli, S. and Sakli, F. (2006) Morphological Characterization of Individual Fiber of Agave americana L. Textile Research Journal, 76, 367-374. http://dx.doi.org/10.1177/0040517506061965

[40] Msahli, S., Sakli, F. and Drean, J.-Y. (2006) Study of Textile Potential of Fibers Extracted from Tunisisan Agave americana L. Autex Research Journal, 6, 9-13.

[41] Belhassen, R., Boufi, S., Vilaseca, F., López, J.P., Méndez, J.A., Franco, E., Pèlach, M.A. and Mutjé, P. (2009) Biocomposites Based on Alfa Fibers and Starch-Based Biopolymer. Polymers for Advanced Technologies, 20, 1068-1075. http://dx.doi.org/10.1002/pat.1364

[42] Triki, A., Omri, M., Guiha, M., Ben Hassen, M., Arous, M. and Kallel, A. (2014) Adhesion Characterization of Alfa Fibres in Unsaturated Polyester Matrix. International Journal of Applied Research on Textiles, 2, 18-29.

[43] Mueller, D., Bhat, G., Kamath, M.G. and Parikh, D.V. (2006) Cotton Nonwovens for Automobiles. 2006 Beltwide Cotton Conferences, San Antonio, 3-6 January 2006, 2460-2464.

[44] Bhat, G.S. (2005) Overview of Cotton Based Nonwovens. 2005 Beltwide Cotton Conferences, New Orleans, 4-7 January 2015, 2644-2646.

[45] Choi, H.-M., Kwon, H.-J. and Moreau, J.P. (1993) Cotton Nonwovens as Oil Spill Cleanup Sorbents. Textile Research Journal, 63, 211-218. http://dx.doi.org/10.1177/004051759306300404

[46] Choi, H.M. and Cloud, R.M. (1992) Natural Sorbents in Oil Spill Cleanup. Environmental Science \& Technology, 26, 772-776. http://dx.doi.org/10.1021/es00028a016

[47] Choi, H.M. (1996) Needlepunched Cotton Nonwovens and Other Natural Fibers as Oil Cleanup Sorbents. Journal of Environmental Science and Health Part A, 31, 1441-1457. http://dx.doi.org/10.1080/10934529609376434 
[48] Bliss, R.M. (2011) Cotton's Potential for Padding Nonwovens. Agricultural Research Service, US Department of Agriculture, Beltsville, 14-17.

[49] Sawhney, A.P.S., Condon, B., Reynolds, M., Slopek, R. and Hui, D. (2010) Advent of Greige Cotton Non-Wovens Made Using a Hydro-Entanglement Process. Textile Research Journal, 80, 1540-1549. http://dx.doi.org/10.1177/0040517510363194

Submit or recommend next manuscript to SCIRP and we will provide best service for you:

Accepting pre-submission inquiries through Email, Facebook, LinkedIn, Twitter, etc. A wide selection of journals (inclusive of 9 subjects, more than 200 journals)

Providing 24-hour high-quality service

User-friendly online submission system

Fair and swift peer-review system

Efficient typesetting and proofreading procedure

Display of the result of downloads and visits, as well as the number of cited articles

Maximum dissemination of your research work

Submit your manuscript at: http://papersubmission.scirp.org/

Or contact as@scirp.org 